\title{
Frequency, Morbidity, and Mortality of Bone Metastases in Advanced Hepatocellular Carcinoma
}

\author{
James J. Harding, MD ${ }^{\mathrm{a}, \mathrm{b}}$; Ghaith Abu-Zeinah, MD ; Joanne F. Chou, MPH ${ }^{\mathrm{a}}$; Dwight Hall Owen, MD; \\ Michele Ly, BS ${ }^{a}$; Maeve Aine Lowery, MDª, ; Marinela Capanu, $\mathrm{PhD}^{\mathrm{a}}$; Richard Do, MDª, \\ Nancy E. Kemeny, MDª, Eileen M. O’Reilly, MDª, Leonard B. Saltz, MDª, ; and Ghassan K. Abou-Alfa, MD a,b
}

\begin{abstract}
Background: Bone metastases are common in hepatocellular carcinoma (HCC), but their incidence, morbidity, and mortality are not well defined. Methods: The Memorial Sloan Kettering Cancer Center database was queried for all patients with HCC and metastases seen from 2002 to 2014 . The prevalence of bone metastasis was determined and cumulative incidence function was used to estimate the probability of developing a bone metastasis. Regression models were created to identify risk factors for osseous metastasis. The frequency of skeletalrelated events (SREs), defined as pathologic fracture, spinal cord compression, need for radiation therapy to bone, and/or surgical resection of bone, was determined and cumulative incidence function was used to estimate the probability of SRE development. Regression models were created to identify SRE risk factors. Correlation of clinicopathologic parameters, including bone metastases and SREs, with overall survival was analyzed using Kaplan-Meier methodology. Results: A total of 459 patients with HCC and extrahepatic metastases were identified; 151 patients (32.9\%) had or developed bone metastases: $128(27.9 \%)$ as a primary site and $23(4.6 \%)$ as a secondary site of extrahepatic disease. Among the 331 patients without bone metastasis at presentation, the yearly incidence of bone metastasis was $6.4 \%$ (95\% $\mathrm{Cl}, 3.6 \%-9.2 \%)$. Hepatitis B virus (HBV) infection increased the chance of developing a bone metastasis $(P=.02)$. The cumulative incidence of SREs was $50 \%$ at 6 months. Univariate analysis showed that patients with HBV-related HCC had a significantly higher incidence of SREs $(P=.02)$. Sorafenib and bisphosphonates each protected against SREs. The presence of SREs was independently associated with a worse overall survival (hazard ratio, $2.13 ; 95 \% \mathrm{Cl}, 1.52-2.97 ; P<.01$ ) in the multivariable model. Conclusions: Patients with AJCC stage IV HCC and bone metastases that are clinically evident on routine radiography or on clinical examination at presentation are apt to develop frequent, morbid, and mortal SREs, whereas those without evident bone metastasis at presentation are unlikely to develop these complications.
\end{abstract}

Bone metastases are common in hepatocellular carcinoma (HCC), occurring in $25.5 \%$ to $38.5 \%$ of patients with extrahepatic disease. ${ }^{1-5}$ As such, major practice guidelines, including those of NCCN, acknowledge the need to evaluate for HCC bone metastases, ${ }^{6-8}$ although they are often vague regarding the clinical course and treatment recommendations for patients with this complication. Furthermore, guidelines for the optimal method, frequency, and patient population to screen for bone metastasis are in flux; currently, screening is rec-

From ${ }^{a}$ Memorial Sloan Kettering Cancer Center, New York, New York; bWeill Cornell Medical College, New York Presbyterian Hospital, New York, New York; and 'Ohio State University, Columbus, Ohio.

Submitted April 28, 2017; accepted for publication August 4, 2017.

The authors have disclosed that they have no financial interests,

arrangements, affiliations, or commercial interests with the manufacturers ommended in symptomatic patients ${ }^{6}$ and mandated as part of the evaluation for transplant candidates. ${ }^{7}$ Due to concerns regarding the utility and cost-effectiveness of screening in transplant candidates, ${ }^{9}$ guidelines for pretransplant screening for osseous spread are likely to be relaxed in the future. Given the uncertainty in dealing with HCC bone metastasis, and because few studies have explored its clinical impact, ${ }^{10}$ we conducted a single-institution retrospective review of patients with HCC and extrahepatic metastases to better understand

of any products discussed in this article or their competitors.

This research was funded in part through the $\mathrm{NIH} / \mathrm{NCI}$ Cancer Center Support Grant P30 CA008748.

Correspondence: James J. Harding, MD, Memorial Sloan Kettering Cancer Center, 300 East 66th Street, New York, NY 10065.

E-mail: Hardinj1@mskcc.org 
Bone Metastases and Hepatocellular Carcinoma

bone metastasis and to develop potential recommendations for screening and management in this population.

\section{Methods}

\section{Study Design}

The Memorial Sloan Kettering Cancer Center (MSKCC) database was queried for all patients with HCC with extrahepatic spread diagnosed by pathology review or established imaging criteria between 2002 and 2014. The study was approved by the MSKCC Institutional Review Board and Privacy Board. Through retrospective chart review, we extracted demographic information (age, sex, race), HCC etiologic factors (eg, hepatitis B virus [HBV] infection, hepatitis $\mathrm{C}$ virus [HCV] infection, alcoholic liver disease, nonalcoholic steatohepatitis [NASH]), liver functionality (Child-Pugh score), HCC characteristics (stage based on AJCC 7th Edition) at initial presentation, time and sites of first metastatic disease, $\alpha$-fetoprotein (AFP) levels at the time of extrahepatic disease, and duration from first metastatic disease to death. Bone metastases were identified by at least one imaging modality. We recorded the initial sites and time of bone metastasis, symptoms related to bone metastasis, initial serum calcium and alkaline phosphatase (ALP) levels, and type of and time to skeletal-related events (SREs), defined as a pathologic fracture, spinal cord compression, and need for radiation and/or surgery to bone. ${ }^{11}$ All types and duration of treatment, including radiation, surgical resection, bisphosphonates, and sorafenib, and the number of SREs per patient were also recorded.

\section{Statistical Analysis}

Descriptive statistics were used to tabulate patient demographics and determine the prevalence of bone metastasis in the cohort. In patients without bone metastases as a first site of extrahepatic disease, cumulative incidence function was used to estimate the probability of developing a bone metastasis. Patients who died without developing an event of interest were treated as competing events. Gray's test was used to compare the cumulative incidence functions by covariates of interest including age, sex, race, treatment era, HCC etiologic risk factor, Child-Pugh score, AFP level, and median calcium and ALP lev- els. Among patients who presented with bone metastasis as a first site of extrahepatic disease, cumulative incidence function was used to estimate the probability of developing an SRE, and Gray's test was used to explore the impact of the covariates of interest on SRE development. The effects of bisphosphonates and sorafenib on SREs were also explored; however, because their effect occurs during administration, and the timing of administration varied among patients, a time-dependent covariate was generated in the competing risk regression model. Covariate differences between bone metastases were tested using Wilcoxon rank sum test for continuous and chi-square test for categorical variables. Overall survival (OS) was calculated from the date of initial metastasis of any type to the date of death, and estimated using KaplanMeier methods or last follow-up. A Cox proportional hazards model was used to evaluate the association between various clinical factors and OS. The model was stratified by year of treatment (2002-2007 vs 2008-2014) to account for subpopulation differences, specifically the approval of sorafenib for HCC. The final multivariable model included clinical and pathologic variables that, in univariate analyses, were correlated with OS with a $P$ value of $\leq 0.2$. SRE was treated as a time-dependent covariate in the univariate and multivariate analyses.

All $P$ values were based on 2 -tailed statistical analysis, and $P<.05$ was considered to indicate statistical significance. All analyses were performed with SAS 9.3 (SAS Institute, Cary, NC) and R version 3.0.1 (R Foundation for Statistical Computing, Vienna, Austria).

\section{Results}

\section{Patient Characteristics and Prevalence of Bone Metastases}

From 2002 to 2014, a total of 640 patients with HCC were identified through a query of the MSKCC institutional database; 181 were excluded due to incorrect coding of $\mathrm{HCC}$ or the absence of extrahepatic disease. The final data set included 459 patients with HCC and extrahepatic disease; 198 presented with extrahepatic disease, whereas 261 (57\%) had recurrent or progressive disease. A total of 151 of 459 patients $(32.9 \%)$ presented with or developed bone metastasis and $128(27.9 \%)$ had bone metastasis as a first site of extrahepatic disease (ie, bone metasta- 
Harding et al

ses must have been a first extrahepatic site, but were not necessarily the only site of extrahepatic disease), whereas 23 (4.6\%) developed bone metastases during the disease course (Table 1). Clinical variables were not appreciably different between patients presenting with or who developed a bone metastases $(\mathrm{N}=151)$ versus those without bone lesions $(\mathrm{N}=308)$. Among patients presenting with or who developed bone metastases, $85 \%$ were male, with a mean age of 64 years (SD, 12). Tumor etiology included 56 (37.1\%) HCV-related, 41 (27.1\%) HBV-related, 26 (17.2\%) alcohol-related, 10 (6.6\%) NASH-related, and $30(19.9 \%)$ of other or unknown etiologies, and $55 \%$ of patients had Child-Pugh A liver function. Other factors, including treatment era, median AFP level, and race, are reported in Table 1.

\section{Characteristics of Bone Metastases}

For patients who presented with bone metastases $(\mathrm{N}=128)$, these lesions occurred predominately in the axial skeleton $(87 \%)$ and were symptomatic in 78 patients $(61 \%)$ (Table 2$)$. The median plasma ALP level was $150 \mathrm{U} / \mathrm{L}$ (range, 57-1,719 U/L) and the median calcium level was $9.2 \mathrm{mg} / \mathrm{dL}$ (range, 7.4-14.1 mg/dL). Hypercalcemia was rare, occurring in only 3 of 128 patients $(2.3 \%)$, represented by calcium levels of 11.1 to $14.1 \mathrm{mg} / \mathrm{dL}$. Most patients $(56.3 \%)$ developed an SRE. These clinical variables were not appreciably different from those in patients who went on to develop a bone metastasis $(\mathrm{N}=23)$.

\section{Incidence of Bone Metastases}

Among the 23 patients who developed bone metastases during the course of follow-up, 20 had symptoms that prompted imaging, whereas 3 had incidentally found lesions. The cumulative incidence of metastasis at 1 year after initial diagnosis of extrahepatic disease was 6.4\% (95\% CI, 3.6\%-9.2\%; Figure 1A). In univariate analysis, race and $\mathrm{HBV}$ status increased the likelihood of developing skeletal metastasis. The

\begin{tabular}{|c|c|c|c|}
\hline & $\begin{array}{l}\text { HCC With Extrahepatic Disease } \\
\text { Without Bone Metastases } \\
\text { ( } \mathrm{N=308)}\end{array}$ & $\begin{array}{l}\text { HCC With Extrahepatic Disease With } \\
\text { Bone Metastases at Presentation } \\
\qquad(\mathrm{N}=128)\end{array}$ & $\begin{array}{l}\text { Extrahepatic Disease With Bone } \\
\text { Metastases Development } \\
(\mathrm{N}=23)\end{array}$ \\
\hline Mean age, y (SD) & $64(13)$ & $65(12)$ & $59(11)$ \\
\hline \multicolumn{4}{|l|}{ Sex, n (\%) } \\
\hline Female & $67(21.8)$ & $19(14.8)$ & $4(17.4)$ \\
\hline \multicolumn{4}{|l|}{ Race, n (\%) } \\
\hline Asian & $45(14.6)$ & $21(16.4)$ & $7(30.4)$ \\
\hline Non-Asian & $257(83.4)$ & $102(79.7)$ & $16(69.6)$ \\
\hline Unknown/Missing & $6(1.9)$ & $5(3.9)$ & $0(0)$ \\
\hline \multicolumn{4}{|l|}{ Etiology, n (\%) } \\
\hline $\mathrm{HCV}$ & $95(30.8)$ & $48(37.5)$ & $8(34.8)$ \\
\hline HBV & $78(25.3)$ & $30(23.4)$ & $11(47.8)$ \\
\hline Alcohol-related & $82(23.5)$ & $21(16.3)$ & $5(21.7)$ \\
\hline $\mathrm{NASH}$ & $24(7.8)$ & $8(6.3)$ & $2(8.7)$ \\
\hline Other & $25(8.1)$ & $28(21.8)$ & $2(8.7)$ \\
\hline \multicolumn{4}{|l|}{ Child-Pugh, n (\%) } \\
\hline A & $147(47.7)$ & $71(55.5)$ & $12(52.2)$ \\
\hline B & $95(30.8)$ & $31(24.2)$ & $6(26.1)$ \\
\hline C & $13(2.8)$ & $0(0)$ & $0(0)$ \\
\hline Missing/Unknown & $53(17.2)$ & $26(20.3)$ & $5(21.7)$ \\
\hline AFP, median (range), ng/mL & $440(1.3-1,023,000)$ & $228.9(0-508,070)$ & $481.2(1.6-162,127)$ \\
\hline \multicolumn{4}{|l|}{ Treatment period, n (\%) } \\
\hline $2002-2007$ & $124(40.3)$ & $48(37.5)$ & $7(30.4)$ \\
\hline 2008-2014 & $184(59.7)$ & $80(62.5)$ & $16(69.5)$ \\
\hline
\end{tabular}

Abbreviation: AFP, $\alpha$-fetoprotein; HBV, hepatitis B virus; HCC, hepatocellular carcinoma; HCV, hepatitis C virus; NASH, nonalcoholic steatohepatitis. aDue to co-occurrence of etiologies, percentages may not add up to $100 \%$. 
Bone Metastases and Hepatocellular Carcinoma

\begin{tabular}{|c|c|c|}
\hline & $\begin{array}{l}\text { Bone Metastases at } \\
\text { Presentation } \\
(\mathrm{N}=128)\end{array}$ & $\begin{array}{l}\text { Bone Metastases } \\
\text { Development } \\
(\mathrm{N}=23)\end{array}$ \\
\hline \multicolumn{3}{|l|}{ Location, n (\%) } \\
\hline Axial & $111(86.7)$ & $20(87)$ \\
\hline Appendicular & $9(7.0)$ & $3(13)$ \\
\hline Both & $8(6.2)$ & $0(0)$ \\
\hline \multicolumn{3}{|l|}{ Symptomatic, n (\%) } \\
\hline Yes & $78(60.9)$ & $20(87)$ \\
\hline No & $30(23.4)$ & $3(13)$ \\
\hline Unknown & $20(15.6)$ & $0(0)$ \\
\hline ALP, median (range), U/L & $150(57-1,719)$ & $151(49-493)$ \\
\hline $\begin{array}{l}\text { Calcium, median } \\
\text { (range), } \mathrm{mg} / \mathrm{dL}\end{array}$ & $9.2(7.4-14.1)$ & $9.2(8.1-10.8)$ \\
\hline \multicolumn{3}{|l|}{ SRE type, n (\%) } \\
\hline None & $56(43.7)$ & $9(39.1)$ \\
\hline Cord compression & $10(7.8)$ & $2(8.7)$ \\
\hline Fracture $^{a}$ & $20(15.6)$ & $4(21.2)$ \\
\hline Radiation $^{a}$ & $35(27.3)$ & $7(30.4)$ \\
\hline Surgery & $7(5.4)$ & $1(4.3)$ \\
\hline $\begin{array}{l}\text { Total number of SREs, } \\
\text { median (range) }\end{array}$ & $2(1-7)$ & $1(1-4)$ \\
\hline
\end{tabular}

Abbreviation: ALP, alkaline phosphatase; HBV, hepatitis B virus; $\mathrm{HCC}$, hepatocellular carcinoma; HCV, hepatitis C virus; NASH, nonalcoholic steatohepatitis; SREs, skeletal-related events.

${ }^{a} 1$ fracture and 3 radiation SREs were excluded from cumulative incidence analysis because the dates of these events were unknown.

cumulative incidences at 1 year between non-Asian and Asian patients were 5.8\% (95\% CI, 2.8\%-8.7\%) versus $10.8 \%$ (95\% CI, $1.6 \%-19.2 \%$ ), respectively $(P=.07$; Figure 1B). The cumulative incidence at 1 year was $11.4 \%$ (95\% CI, $4.3 \%-18.6 \%$ ) for patients with HBV infection versus $4.6 \%$ (95\% CI, $1.8 \%-7.4 \%)$ for those without $(P=.02$; Figure $1 \mathrm{C})$. Asian patients were significantly more likely to have a confirmed HBV infection than non-Asian patients ( $80 \%$ vs $17 \% ; P<.01)$. No other disease-specific factors modulated the chance of developing osseous disease. Osseous disease was rarely observed $>1$ year after the diagnosis of extrahepatic disease, likely due to the expected survival of patients with HCC and known metastases.

\section{Incidence of SREs}

We evaluated the 128 patients who presented with bone metastasis to assess for proportion, type, and frequency of SREs (Table 2). Median follow-up from the time of SRE was 4.3 months (range, 0.03-38.6
A

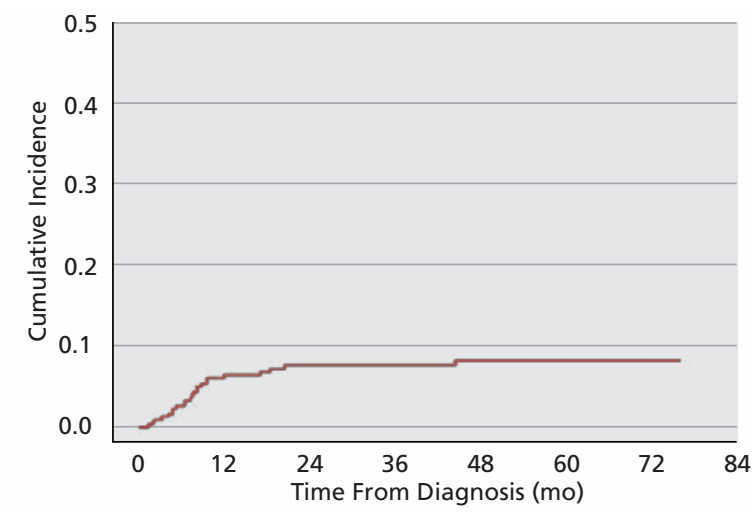

B

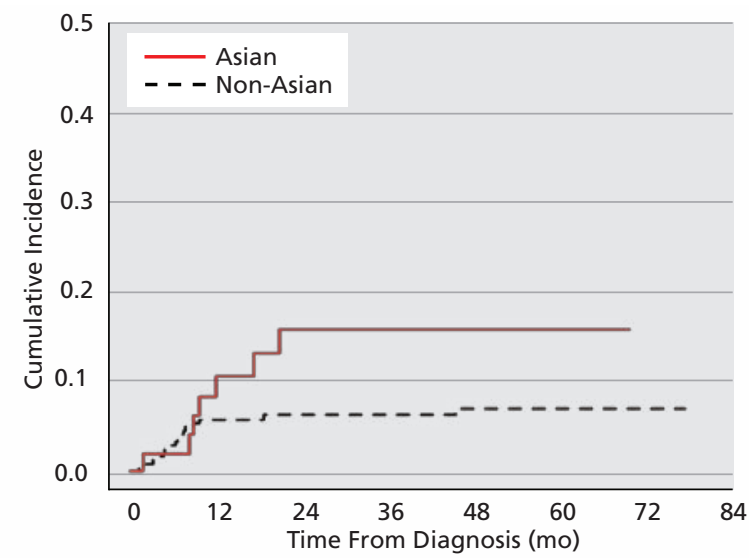

C

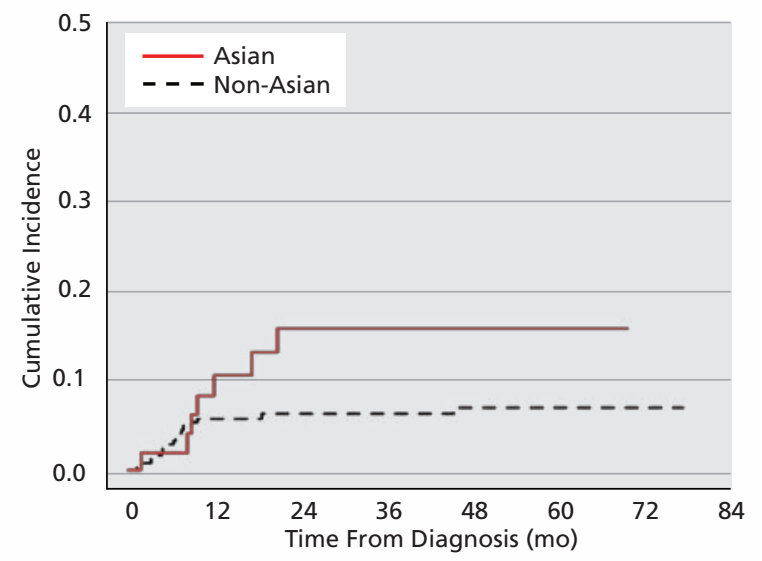

Figure 1. Incidence of bone metastasis in patients with extrahepatic hepatocellular carcinoma (HCC). The cumulative incidence over time (months) to the development of HCC skeletal metastasis, with death as a competing risk factor, in (A) patients with extrahepatic disease, (B) non-Asians versus Asians, and (C) hepatitis B virus (HBV) versus not.

months). A total of 72 patients (56.3\%) had at least one SRE after diagnosis of bone metastasis, with a median time to first SRE of 0.8 months (range, 0.0321.0 months). The first SREs included 35 irradiated bone lesions, 20 pathologic fractures ( 9 vertebral, 5 rib, 4 femoral, and 2 pelvic bones), 10 spinal cord compressions, and 7 surgeries to bone. The median 
Harding et al

number of SREs per patient was 2 (range, 1-7). The first SREs occurred rapidly after the identification of osseous disease, with 1-, 3-, and 6-month cumulative incidences of 30\% (95\% CI, 22\%-38\%), 43\% (95\% CI, 35\%-52\%), and 50\% (95\% CI, 41\%-59\%), respectively (Figure 2A). Among the 72 patients who had an SRE, we observed that 41 had a second SRE, with a median time to this event of 0.9 months. Before the second SRE, 13 patients had prior radiation
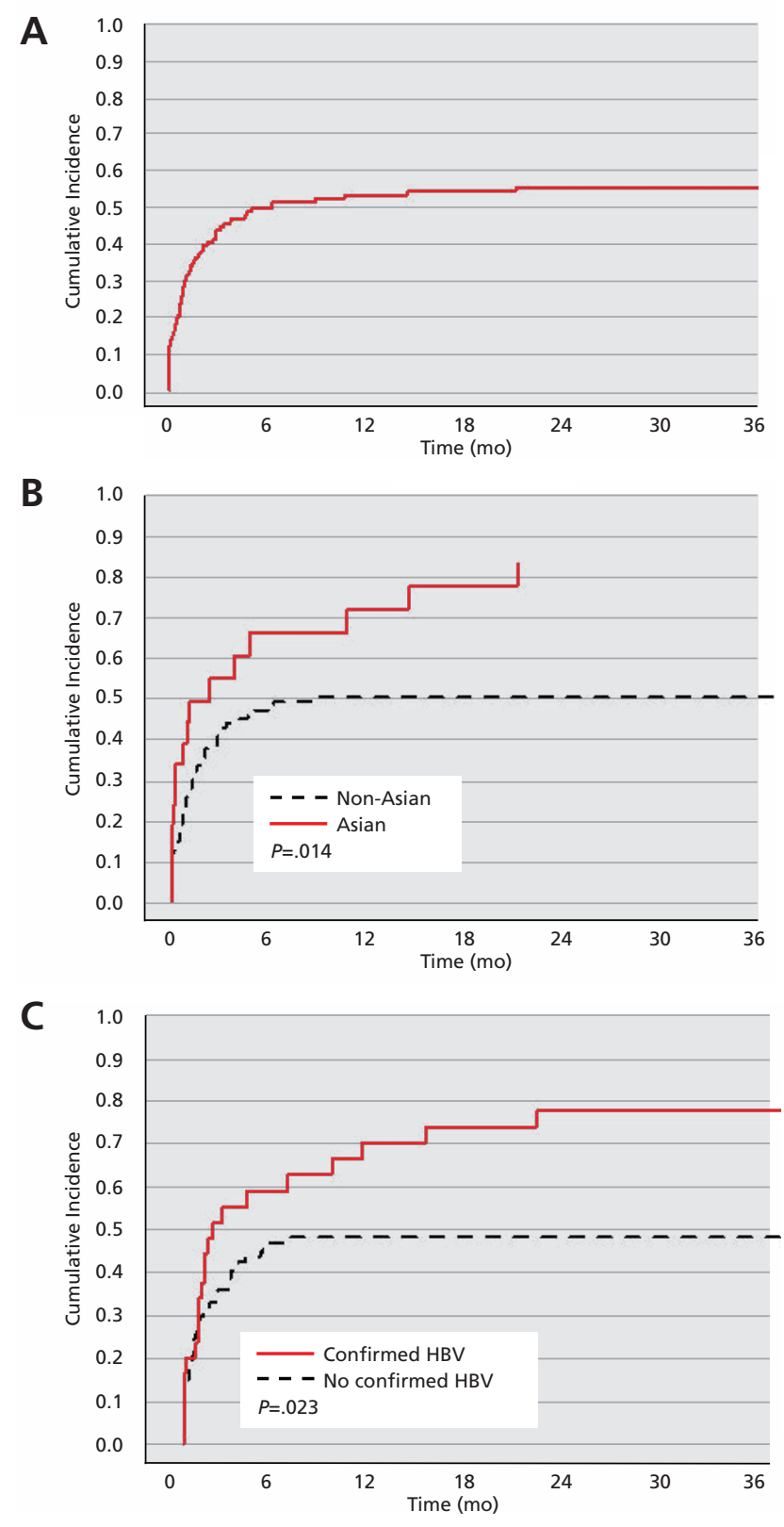

Figure 2. Incidence of skeletal-related events (SREs) in patients with hepatocellular carcinoma osseous metastasis. The cumulative incidence over time (months) to the development of SREs, with death as a competing risk factor, in (A) all patients with bone metastasis, (B) nonAsians versus Asians, and (C) hepatitis B virus (HBV) versus not. to bone, 9 received bisphosphonates, and 15 received sorafenib.

\section{Correlation of Clinicopathologic Parameters and SREs}

A greater incidence of SREs was associated with race (Figure 2B; $66 \%$ vs $47 \%$ for Asian vs nonAsian incidence of SRE at 6 months, respectively; $P=.01$ ) and HBV positivity (Figure 2C; $58 \%$ vs $46 \%$ for HBV positivity vs not, respectively; $P=.02$ ). The unadjusted hazard ratios (HRs) for bisphosphonates and sorafenib therapy were $0.3(0.13-0.64 ; P<.01)$ and $0.4(0.19-0.77 ; P<.02)$, respectively. No other disease-specific factors modulated the chance of developing SREs.

\section{Bone Metastasis, SREs, and Patient Outcome}

Median follow-up for the entire cohort was 6 months (range, $0.03-72$ months). At last assessment, 89 of 459 patients were alive. Median survival for the cohort was 5.6 months (95\% CI, 4.6-6.9). Factors significantly associated with $O S$ on univariate analysis were age, AFP level, NASH-associated HCC, Child-Pugh score, and SREs (Table 3). As previously shown, high AFP levels in patients with HCC and extrahepatic disease portends a poor prognosis (HR, 1.9; 95\% CI, 1.5-2.4; P<.01). Consistent with emerging data, NASH appeared to be a positive prognostic factor (HR, 0.60; 95\% CI, 0.39-0.92)..$^{12}$ Liver function was a negative prognostic factor (ChildPugh B7: HR, 2.22; 95\% CI, 1.66-2.97; Child-Pugh B8 and 9: HR, 2.34; 95\% CI, 1.71-3.20; and ChildPugh C: HR, 1.73; 95\% CI, 0.93-3.20; $P<.01$ ). The presence or absence of bone metastasis at presentation of extrahepatic disease had no impact on OS; however, SREs were associated with worse OS (HR, $1.5 ; 1.16-2.05 ; P<.01)$. Multivariate analysis confirmed that AFP levels, Child-Pugh score, and SREs were independently associated with a poor outcome in patients with extrahepatic HCC, with SREs having an HR of 2.13 (95\% CI, 1.52-2.97; P<.01).

\section{Discussion}

The present study is one of the largest single-center series of HCC-associated bone metastases. We identified and confirmed that HCC bone metastases are relatively common; most patients with bone metastases $(85 \%)$ will present with such lesions as 
Bone Metastases and Hepatocellular Carcinoma

\begin{tabular}{|c|c|c|c|c|}
\hline \multirow[b]{2}{*}{ Characteristics } & \multicolumn{2}{|c|}{ Univariate } & \multicolumn{2}{|c|}{ Multivariate } \\
\hline & HR $(95 \%$ Cl) & $P$ Value & HR $(95 \%$ Cl) & $P$ Value \\
\hline $\mathrm{Age}^{\mathrm{b}}$ & $1.1(0.98-1.25)$ & .09 & $1.1(0.94-1.28)$ & .22 \\
\hline Bone metastasis at presentation & & .76 & & \\
\hline Yes & $1.04(0.82-1.30)$ & & & \\
\hline No & 1.00 & & & \\
\hline Sex, n (\%) & & .16 & & .68 \\
\hline Male & $1.21(0.92-1.58)$ & & $1.07(0.77-1.48)$ & \\
\hline Female & 1.00 & & & \\
\hline Race, n (\%) & & .053 & & .12 \\
\hline Asian & $0.75(0.56-1.004)$ & & $0.76(0.54-1.07)$ & \\
\hline Non-Asian & 1.00 & & & \\
\hline AFP, ng/mL & & $<.01$ & & $<.01$ \\
\hline$>360.50$ & $1.9(1.5-2.4)$ & & $1.8(1.43-2.42)$ & \\
\hline$\leq 360.50$ & 1.00 & & & \\
\hline \multicolumn{5}{|l|}{ Etiology, n (\%) } \\
\hline $\mathrm{HBV}$ & $0.92(0.73-1.17)$ & .53 & & \\
\hline $\mathrm{HCV}$ & $1.14(0.91-1.41)$ & .24 & & \\
\hline Alcohol-related & $1.02(0.79-1.29)$ & .90 & & \\
\hline NASH & $0.60(0.39-0.92)$ & .01 & $0.9(0.53-1.58)$ & .76 \\
\hline Child-Pugh, n (\%) & & $<.01$ & & $<.01$ \\
\hline$A$ & 1.00 & & 1.00 & \\
\hline B7 & $2.22(1.66-2.97)$ & & $2.05(1.49-2.81)$ & \\
\hline B8/B9 & $2.34(1.71-3.20)$ & & $2.42(1.68-3.48)$ & \\
\hline$C$ & $1.73(0.93-3.20)$ & & $2.58(1.32-5.03)$ & \\
\hline Presence of $S R E s^{c}$ & $1.54(1.16-2.05)$ & $<.01$ & $2.13(1.52-2.97)$ & $<.01$ \\
\hline
\end{tabular}

Abbreviations: AFP, $\alpha$-fetoprotein; HBV, hepatitis B virus; HCV, hepatitis C virus; HR, hazard ratio; NASH, nonalcoholic steatohepatitis; SREs, skeletal-related events.

aAnalyses were stratified by treatment period (2002-2007 vs 2008-2014).

ber 15 year increase in age.

cPresence of SRE was treated as a time-dependent variable in the Cox proportional hazards model.

a primary extrahepatic site of disease. In patients with extrahepatic disease who do not have skeletal disease at presentation, the incidence of bone metastasis development is low, and when it does arise, it is often symptomatic and unlikely to occur after the first year of follow-up. Among patients with osseous disease as an initial extrahepatic manifestation of HCC, most will rapidly develop SREs, particularly those of Asian descent and with HBV-associated HCC. Sorafenib and bisphosphonate treatment may be protective against SREs. Although bone metastases do not portend a worse outcome, SREs are an independent prognostic factor associated with poor OS. These findings imply a unique biology of HCC osseous lesions.

There are several limitations to our study, namely that the single-center retrospective design intro- duces referral and ascertainment bias. Furthermore, although the data suggest that screening for bone metastases at earlier stages may be needed, the optimal patient population to screen, modality, and frequency of screening are currently unclear. Regarding treatment, because bisphosphonates and sorafenib were treated as time-dependent covariates, we could not interrogate the individual contribution of each therapy to SRE outcome; it is possible that the sorafenib treatment effect was the main driver of benefit. Finally, tissue-specific correlates were not explored in this cohort analysis but are needed in the future.

From a clinical perspective, our work supports the observation that SREs are morbid events that diminish quality of life and increase the economic burden and healthcare utilization costs. ${ }^{13,14}$ Impressively, 
Harding et al

$>50 \%$ of patients who presented with osseous metastases went on to develop an SRE within 6 months of their detection. As observed in other solids tumors but not previously in HCC, SREs are independently associated with poor survival in advanced HCC after adjusting for other potential confounders. ${ }^{15-17}$ Diminished survival is not unexpected-SREs worsen performance status, impair access or interrupt systemic therapy, and may require operative management or radiotherapy and/or lead to spinal cord compression. Importantly, metastases to the spine, but not other sites, have been associated with a decrease in OS in patients with HCC. ${ }^{10}$

Given the high frequency of SREs in advanced HCC and their deleterious effect on survival, a screening and treatment approach should be delineated for bone metastases in patients with HCC. To date, there are limited screening and management guidelines for HCC-related skeletal disease. ${ }^{6-8}$ The data presented herein help fill this void, support current recommendations, and call attention to this important clinical problem. Based on these retrospective data and our literature review, we provide our institutional recommendations to guide clinical practice for patients with HCC and bone metastases. Perhaps the most powerful observation is that patients who present with extrahepatic disease but without bone lesions are unlikely to develop skeletal disease. This observation presumably reflects differential biology and short survival in the metastatic setting. It also indicates that routine surveillance after the development of extrahepatic disease, with bone scans or other modalities geared at assessing bone lesions, will yield little benefit. Furthermore, because nearly all of such lesions are indeed symptomatic, a symptom-directed approach is more sensible and economical in this population. On the contrary, at the time of extrahepatic disease, most bone metastases are easily detectable with standard clinical and radiographic assessments. The critical question remaining is whether a screening algorithm should be applied to earlier stages of disease. Large prospective observational cohorts will be required to determine whether screening for bone lesions in high-risk, liver-limited HCC is warranted, useful, and cost-effective. ${ }^{18-20}$ Until such data are available, we do not recommend routine screening for bone lesions in the absence of patient-reported symptoms.
When bone metastases are documented, a prompt multidisciplinary review with the application of radiation, operative, or combined modality management dictated by the clinical scenario should ensue. Our data suggest that bisphosphonates and HCC-directed systemic therapy should decrease the risk of SRE development. Indeed, clinical trials of the bisphosphonate zoledronic $\operatorname{acid}^{21,22}$ and the RANKL inhibitor denosumab, ${ }^{23}$ which demonstrated the protective effects of bone-modifying agents against SREs, did not include a large proportion of patients with advanced HCC. Furthermore, because the protective effects of bisphosphates are only observed with extended treatment, which exceeds the historic median OS of patients with HCC, one might question the utility of bisphosphonates in aggressive tumor types with poor outcomes in general. Nevertheless, our data, several anecdotes, and other series suggest a benefit with such agents. ${ }^{10,24-26}$ In the absence of a formal clinical trial in HCC, the available evidence indicates that bisphosphonate therapy is reasonable in patients with intact hepatic function and bone lesions. The observation that sorafenib reduces the risk of SREs is consistent with its documented antitumor activity. ${ }^{27}$ One must be cautious of overinterpreting the protective effects of sorafenib on HCC-associated SREs, however, because it is possible that the observed SRE HR reduction related to sorafenib is driven by the relative contraindication of sorafenib, an antiangiogenic and radiosensitizer, in the setting of surgery or radiation therapy. Our expectation is that emerging therapies for HCC, including those targeting immune checkpoint molecules, would similarly prevent SREs. ${ }^{28}$ However, interestingly, early reports suggest that the specific metastatic site may predict for differential outcome to immunotherapy due to altered immune competence of different organs. ${ }^{28,29}$

A predictive nomogram for patients with HCC at risk of developing osseous complications would be ideal, specifically to prevent pathologic fractures and improve patient outcomes. In other disease systems, performance status, tumor histology, and serologic markers are predictive of SREs. ${ }^{30-35}$ With the exception of Asian race and HBV infection, no other patient-specific or tumor-specific factor had any impact on SRE development. The covariates of Asian ancestry and HBV infection represent the observed epidemiology of global HBV infection and are de- 
Bone Metastases and Hepatocellular Carcinoma

pendent variables in our analysis. ${ }^{36} \mathrm{HBV}$-associated HCC may behave more aggressively and appears to have worse outcomes compared with HCV-associated HCC, despite sorafenib treatment. ${ }^{37}$ It remains unclear whether the higher incidence of bone metastases and SREs in HBV-associated HCC is indicative of true biologic phenomena or epiphenomena, which is not controlled for in the retrospective analysis.

Zheng et $\mathrm{al}^{38}$ have proposed that stromal signals resembling distant organ sites may select for cancer cells primed for metastasis in that organ. Preclinical and translational data demonstrate a differential expression of 67 genes between HCC primary tumors that ultimately metastasize to bone versus another site. ${ }^{39,40}$ Specifically, high-level expression of tumoral connective tissue growth factor, interleukin-11, and matrix metalloproteinase-1 from curative resected specimens is correlated with a higher risk of developing bone metastases. ${ }^{41}$ The clinical data reported herein are hypothesis-generating in that these data support a unique biology for HCC osseous lesions.

\section{References}

1. Okazaki N, Yoshino M, Yoshida T, et al. Bone metastasis in hepatocellular carcinoma. Cancer 1985;55:1991-1994.

2. Uchino K, Tateishi R, Shiina S, et al. Hepatocellular carcinoma with extrahepatic metastasis: clinical features and prognostic factors. Cancer 2011;117:4475-4483.

3. Katyal S, Oliver JH III, Peterson MS, et al. Extrahepatic metastases of hepatocellular carcinoma. Radiology 2000;216:698-703.

4. Natsuizaka M, Omura T, Akaike T, et al. Clinical features of hepatocellular carcinoma with extrahepatic metastases. J Gastroenterol Hepatol 2005;20:1781-1787.

5. Fukutomi M, Yokota M, Chuman $\mathrm{H}$, et al. Increased incidence of bone metastases in hepatocellular carcinoma. Eur J Gastroenterol Hepatol 2001;13:1083-1088.

6. Benson AB III, D'Angelica MI, Abbott DE, et al. NCCN Guidelines Insights: Hepatobiliary Cancers, Version 1.2017. J Natl Compr Canc Netw 2017;15:563-573.

7. European Association for the Study of the Liver; European Organisation for Research and Treatment of Cancer. EASL-EORTC clinical practice guidelines: management of hepatocellular carcinoma. J Hepatol 2012;56:908-943

8. Martin P, DiMartini A, Feng S, et al. Evaluation for liver transplantation in adults: 2013 practice guideline by the American Association for the Study of Liver Diseases and the American Society of Transplantation. Hepatology 2014;59:1144-1165.

9. Rodriguez S, Balbinotto Neto G, Kiss G, et al. Cost-effectiveness of whole-body bone scans in the pre-liver transplant assessment of patients with hepatocellular carcinoma in Southern Brazil. Clin Transplant 2016;30:399-406.

10. Santini D, Pantano F, Riccardi F, et al. Natural history of malignant bone disease in hepatocellular carcinoma: final results of a multicenter bone metastasis survey. PLoS One 2014;9:e105268.

11. Gralow JR, Biermann JS, Farooki A, et al. NCCN task force report: bone health in cancer care. J Natl Compr Canc Netw 2013;11(Suppl 3):S1-50; quiz S51.
That is, patients with nonosseous extrahepatic disease are very unlikely to develop bony lesions.

\section{Conclusions}

This study demonstrates that one-third of patients with HCC and extrahepatic metastasis will present with or develop a bone metastasis. Most of these patients will go on to develop morbid SREs. Such events are independently associated with a worse OS, and may be higher risk in patients with HBV infection, with reduced incidence in patients treated with bisphosphonates and sorafenib. We therefore recommend an aggressive clinical and radiologic assessment at the time of metastatic disease diagnosis. In patients with metastatic disease but not to bone, the risk of bone metastasis is low, and therefore formal radiographic screening is not required and may be directed by patient symptoms. Our data and the current literature indicate that a high prevalence of HCC osseous lesions in advanced disease argues for a deeper understanding of HCC biology.

12. Frades I, Andreasson E, Mato JM, et al. Integrative genomic signatures of hepatocellular carcinoma derived from nonalcoholic fatty liver disease. PLoS One 2015;10:e0124544.

13. Hagiwara M, Delea TE, Chung K. Healthcare costs associated with skeletal-related events in breast cancer patients with bone metastases. J Med Econ 2014;17:223-230.

14. Jayasekera J, Onukwugha E, Bikov K, Hussain A. The economic burden of skeletal-related events among elderly men with metastatic prostate cancer. Pharmacoeconomics 2014;32:173-191.

15. Terpos E, Moulopoulos LA, Dimopoulos MA. Advances in imaging and the management of myeloma bone disease. J Clin Oncol 2011;29:1907-1915.

16. Howard LE, De Hoedt AM, Aronson WJ, et al. Do skeletal-related events predict overall survival in men with metastatic castration-resistant prostate cancer? Prostate Cancer Prostatic Dis 2016;19:380-384

17. Yong $\mathrm{M}$, Jensen $\mathrm{AO}$, Jacobsen JB, et al. Survival in breast cancer patients with bone metastases and skeletal-related events: a populationbased cohort study in Denmark (1999-2007). Breast Cancer Res Treat 2011;129:495-503.

18. Cha C, Fong Y, Jarnagin WR, et al. Predictors and patterns of recurrence after resection of hepatocellular carcinoma. J Am Coll Surg 2003;197:753758.

19. Shah SA, Greig PD, Gallinger S, et al. Factors associated with early recurrence after resection for hepatocellular carcinoma and outcomes. J Am Coll Surg 2006;202:275-283.

20. Shah SA, Cleary SP, Wei AC, et al. Recurrence after liver resection for hepatocellular carcinoma: risk factors, treatment, and outcomes. Surgery 2007;141:330-339.

21. Rosen LS, Gordon D, Tchekmedyian NS, et al. Long-term efficacy and safety of zoledronic acid in the treatment of skeletal metastases in patients with nonsmall cell lung carcinoma and other solid tumors: a randomized, phase III, double-blind, placebo-controlled trial. Cancer 2004;100:26132621.

22. Rosen LS, Gordon D, Tchekmedyian S, et al. Zoledronic acid versus placebo in the treatment of skeletal metastases in patients with lung cancer and other solid tumors: a phase III, double-blind, randomized trial-the Zoledronic Acid Lung Cancer and Other Solid Tumors Study group. J Clin Oncol 2003;21:3150-3157. 
Harding et al

23. Fizazi K, Caducci M, Smith M, et al. Denosumab versus zoledronic acid for treatment of bone metastases in men with castration-resistant prostate cancer: a randomised, double-blind study. Lancet 2011;377:813-822.

24. Montella L, Addeo R, Palmieri G, et al. Zoledronic acid in the treatment of bone metastases by hepatocellular carcinoma: a case series. Cancer Chemother Pharmacol 2010;65:1137-1143.

25. Katamura $Y$, Aikata $H$, Hashimoto $Y$, et al. Zoledronic acid delays disease progression of bone metastases from hepatocellular carcinoma. Hepatol Res 2010;40:1195-1203.

26. Liu Q, Tao YH, Bai RZ, et al. Zoledronic acid inhibits growth of hepatocellular carcinoma cells in vitro and in vivo. Chin Med J (Engl) 2013;126:1486-1490.

27. Harding JJ, Abou-Alfa GK. Treating advanced hepatocellular carcinoma: how to get out of first gear. Cancer 2014;120:3122-3130.

28. Harding JJ, El Dika I, Abou-Alfa GK. Immunotherapy in hepatocellular carcinoma: primed to make a difference? Cancer 2016;122:367-377.

29. Tumeh PC, Hellmann MD, Hamid $O$, et al. Liver metastasis and treatment outcome with anti-PD-1 monoclonal antibody in patients with melanoma and NSCLC. Cancer Immunol Res 2017;5:417-424.

30. Sun JM, Ahn JS, Lee S, et al. Predictors of skeletal-related events in non-small cell lung cancer patients with bone metastases. Lung Cancer 2011;71:89-93.

31. Smith MR, Cook RJ, Coleman R, et al. Predictors of skeletal complications in men with hormone-refractory metastatic prostate cancer. Urology 2007;70:315-319.

32. Saad F, Segal S, Eastham J. Prostate-specific antigen kinetics and outcomes in patients with bone metastases from castration-resistant prostate cancer treated with or without zoledronic acid. Eur Urol 2014;65:146-153.
33. Mylin AK, Abildgaard N, Johansen JS, et al. Serum YKL-40: a new independent prognostic marker for skeletal complications in patients with multiple myeloma. Leuk Lymphoma 2015;56:2650-2659.

34. de la Piedra C, Alcaraz A, Bellmunt J, et al. Usefulness of bone turnover markers as predictors of mortality risk, disease progression and skeletal related events appearance in patients with prostate cancer with bone metastases following treatment with zoledronic acid: TUGAMO study. $\mathrm{Br}$ J Cancer 2013;108:2565-2572.

35. Brown JE, Cook RJ, Major $\mathrm{P}$, et al. Bone turnover markers as predictors of skeletal complications in prostate cancer, lung cancer, and other solid tumors. J Natl Cancer Inst 2005;97:59-69.

36. Chang IC, Huang SF, Chen PJ, et al. The hepatitis viral status in patients with hepatocellular carcinoma: a study of 3843 patients from Taiwan Liver Cancer Network. Medicine (Baltimore) 2016;95:e3284.

37. Cheng AL, Kang YK, Lin DY, et al. Sunitinib versus sorafenib in advanced hepatocellular cancer: results of a randomized phase III trial. J Clin Oncol 2013;31:4067-4075.

38. Zhang XH, Jin X, Malladi S, et al. Selection of bone metastasis seeds by mesenchymal signals in the primary tumor stroma. Cell 2013;154:10601073.

39. Xiang ZL, Zeng ZC, Tang ZY, et al. Potential prognostic biomarkers for bone metastasis from hepatocellular carcinoma. Oncologist 2011;16:10281039.

40. Xiang ZL, Zeng ZC, Tang ZY, et al. Chemokine receptor CXCR4 expression in hepatocellular carcinoma patients increases the risk of bone metastases and poor survival. BMC Cancer 2009;9:176.

41. Xiang ZL, Zeng ZC, Fan J, et al. Gene expression profiling of fixed tissues identified hypoxia-inducible factor-1alpha, VEGF, and matrix metalloproteinase-2 as biomarkers of lymph node metastasis in hepatocellular carcinoma. Clin Cancer Res 2011;17:5463-5472.

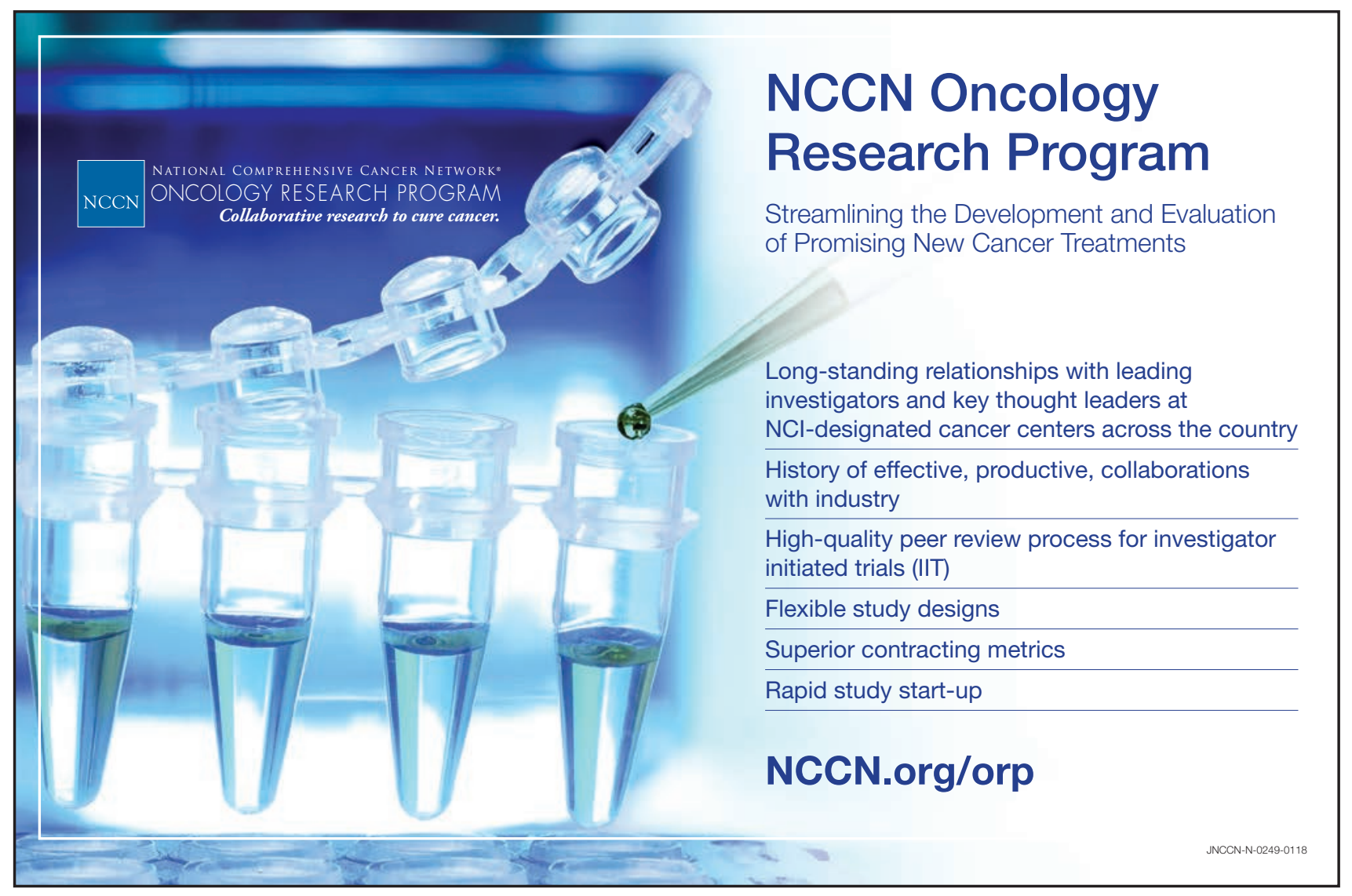

